\title{
Modified phosphatidylcholine with different alkyl chain length and covalently attached caffeic acid affects the physical and oxidative stability of omega-3 delivery $70 \%$ oil-in- water emulsions
}

Yesiltas, Betül; Moltke Sørensen, Ann-Dorit ; García Moreno, Pedro Jesús; Anankanbil, Sampson; Guo, Zheng; Jacobsen, Charlotte

Published in:

Food Chemistry

Link to article, DOI:

10.1016/j.foodchem.2019.03.087

Publication date:

2019

Document Version

Peer reviewed version

Link back to DTU Orbit

Citation (APA):

Yesiltas, B., Moltke Sørensen, A-D., García Moreno, P. J., Anankanbil, S., Guo, Z., \& Jacobsen, C. (2019).

Modified phosphatidylcholine with different alkyl chain length and covalently attached caffeic acid affects the physical and oxidative stability of omega-3 delivery 70\% oil-in-water emulsions. Food Chemistry, 289, 490-499. https://doi.org/10.1016/j.foodchem.2019.03.087

\section{General rights}

Copyright and moral rights for the publications made accessible in the public portal are retained by the authors and/or other copyright owners and it is a condition of accessing publications that users recognise and abide by the legal requirements associated with these rights.

- Users may download and print one copy of any publication from the public portal for the purpose of private study or research.

- You may not further distribute the material or use it for any profit-making activity or commercial gain

- You may freely distribute the URL identifying the publication in the public portal 


\section{Highlights}

- Increased amount of modified phosphatidylcholine(PC)s improved physical stability

- Modified PCs enhanced antioxidant activity at the oil-water interface

- Having caffeic acid attached to PC significantly improved oxidative stability

- Modified PC_C16 led to a higher surface protein load compared to PC_C14 
1 Modified phosphatidylcholine with different alkyl chain length and covalently attached

2 caffeic acid affects the physical and oxidative stability of omega-3 delivery $70 \%$ oil-in-

3 water emulsions

4 Betül Yesiltas ${ }^{1}$, Ann-Dorit M. Sørensen ${ }^{1}$, Pedro J. García-Moreno', Sampson Anankanbil²,

5 Zheng $\mathrm{Guo}^{2}$, Charlotte Jacobsen ${ }^{1}$

$6 \quad{ }^{1}$ National Food Institute, Technical University of Denmark, Lyngby, Denmark

$7 \quad{ }^{2}$ Department of Engineering, Aarhus University, Aarhus, Denmark

8 *Correspondence: Charlotte Jacobsen, National Food Institute, Technical University of

9 Denmark, Kemitorvet, Building 204, 2800 Kgs. Lyngby, Tel: +45 232790 75; e-mail:

10 chja@food.dtu.dk

11

12

13

14

15

16

17

18

19 


\section{Abstract}

21 This study investigated the effects of modified phosphatidylcholine (PC) with different alkyl chain lengths (PC_C14 and PC_C16) and covalently attached caffeic acid on the physical and oxidative stability of $70 \%$ fish oil-in-water emulsions. High fat emulsions were produced using different amounts of modified PCs in combination with sodium caseinate and soy-PC. Results showed that the physical stability of the emulsions was improved with increasing concentrations of modified PCs, due to their high surface activity. Emulsion stabilized with equivalent concentrations.

Key words: modified phospholipids; phosphatidylcholine; sodium caseinate; lipid oxidation; oil-water interface; caffeic acid; high fat delivery emulsions 
41 Evidences for health benefits of long chain (LC) omega-3 (n-3) polyunsaturated fatty acids 42 (PUFAs), such as eicosapentaenoic acid (EPA, 20:5n-3) and docosahexaenoic (DHA, 22:6n3) have been increasing in the last decades. Some of the effects include decreasing the risk of cardiovascular diseases, improving brain development in infants, maintaining normal blood pressure and triglyceride levels in the blood, supporting mental health as well as immune system (Calder \& Yaqoob, 2012; Song et al., 2016; Cheatham, Colombo, \& Carlson, 2006).

LC n-3 PUFAs are mainly available in marine fish and fish products. However, the consumption of these LC n-3 PUFAs is inadequate in most Western countries (EFSA, 2010). Therefore, increasing the consumption of these bioactive compounds has attracted interest from food researchers and industry. Due to easier hydrogen abstraction from the bis-allylic positions, LC n-3 PUFAs are highly prone to oxidation (Frankel, 2012b). Oxidation causes loss of nutritional value and the formation of undesired off-flavors. Therefore, delivery systems have been developed in order to protect LC n-3 PUFAs against lipid oxidation. One of the delivery systems for LC n-3 PUFAs is oil-in-water emulsions. High fat (70\%) oil-in-water emulsions were found to be advantageous for enrichment of high fat content food products with LC n-3 PUFAs (Horn et al., 2011; Yesiltas et al., 2018a,b).

Previous studies focused on different ways of improving physical properties of the oil-water interface as well as enhancing the oxidative stability of the oil-in-water emulsion system. The strategies studied include to: i) use phenolipids with various alkyl chain lengths and phenolic 60 compounds (Laguerre et al., 2009; Sørensen et al., 2014; Alemán et al., 2015; Sørensen et 
al., 2017), ii) incorporate emulsifiers with antioxidant activities (Yesiltas et al., 2019), iii) add free antioxidants in the emulsion along with emulsifiers (Sørensen et al., 2008), or iv) to have emulsifiers modified with various alkyl chains and covalently attached phenolic acids (Anankanbil et al., 2018; Yesiltas et al., 2018b).

One of the approaches to limit lipid oxidation whilst ensuring an acceptable physical stability is engineering an interfacial layer with optimal properties to resist oxidation, as oxidation has been claimed to be initiated at the interface (Berton-Carabin et al., 2014). In order to have a bioinspired interface structure, proteins and phospholipids could be used in combination. Such a combination of emulsifiers has been suggested to form an interface structure providing a better coverage of the oil droplets compared to a single emulsifier (Fang and Dalgleish, 2016; García-Moreno et al., 2014; Berton-Carabin et al., 2018; Yesiltas et al., 2019), which could provide a good physical barrier for prooxidants' diffusion into the oil phase.

Previous studies have focused on the antioxidant activity at the oil-water interface of the oil-inwater emulsions (Laguerre et al., 2013; Berton-Carabin et al., 2014, 2018). However, lipophilicity of the surface active antioxidative compound has an important effect on its antioxidative activity in heterogeneous systems. Based on polar paradox and cut-off effect theories, researchers have focused on finding the most efficient lipophilicity for particular surface active compounds with antioxidant activity in emulsion systems. In the studies conducted using phenolipids with various lipophilicity, it was observed that the most efficient alkyl chain lengths could be system and particular compound dependent (Laguerre et al., 2013; Alemán et al., 2015; Sørensen et al., 2017). 
Caffeic acid is a commonly used antioxidant with radical scavenging and metal chelating (especially iron) activities and its efficacy has been shown to be dependent on $\mathrm{pH}$, addition of iron and emulsifier type (Gülcin, 2006; Sørensen et al., 2008). The antioxidative properties (radical scavenging and reducing power) of caffeic, ferulic and coumaric acids and their derivatives were reported in a previous study. Caffeic acid and caffeates had the highest radical scavenging and metal chelating activities, whereas the lowest radical scavenging and metal chelating activities were measured for coumaric acid and coumarates (Sørensen et al., 2014). The effect of the alkyl chain length on antioxidant efficacy has also been studied for caffeic acid esters. It was found that the medium alkyl chain length caffeic acid (octyl caffeate) had higher antioxidant activity compared to shorter and longer alkyl chain lengths in $40 \%$ soybean oil-in-water emulsions (Costa, Losada-Barreiro, Paica-Martinsa, and Bravo-Díaz, 2017). Similar results were obtained when alkyl caffeates were applied in fish oil enriched mayonnaise; short to medium alkyl chain ( $\mathrm{C} 4, \mathrm{C} 8$, and $\mathrm{C} 12)$ caffeic acid were found to be more effective antioxidants (Alemán et al., 2015). Another study carried out with modified diacetyl tartaric acid esters of mono- and diglycerides (DATEM) with covalently attached caffeic acid and C12 or C14 alkyl chain lengths showed that the modified DATEM with C14 chain length provided slightly better oxidative stability compared to the modified DATEM with C12 chain length in $70 \%$ fish oil-in-water emulsions produced with sodium caseinate (CAS), DATEM and modified DATEMs (Yesiltas et al., 2018b).

The aim of this study was to investigate the effect of modified phosphatidylcholine (PC) with covalently attached caffeic acid and different alkyl chain lengths on physical and oxidative stability of $70 \%$ fish oil-in-water emulsions stabilized by sodium caseinate, soy PC and 
105 modified PCs. Soy PC and modified PC in combination with CAS was used in order to 106 decrease the viscosity of the high fat omega-3 delivery emulsions when compared to

107 emulsions stabilized only with CAS. This will make it easier to apply the delivery emulsions in 108 food systems. It was hypothesized that incorporation of modified PCs in the $70 \%$ fish oil-in109 water emulsions will lead to a more pronounced reduction in interfacial tension compared to 110 conventional PC with 2 alkyl chains. Thus, this will result in emulsions with enhanced physical 111 stability. Moreover, different chain length (C14 and C16) of modified PCs is expected to have 112 an impact on adsorption of the molecule at the oil-water interface of the emulsions due to the 113 different hydrophilic-lipophilic balance (HLB) values. In addition, modified PCs with covalently

114 attached caffeic acid are expected to enhance oxidative stability of the emulsions compared 115 to physical mixtures of soy PC and free caffeic acids with the strategy of bringing the phenolic 116 compounds with antioxidant activity into the vicinity of the interface taking advantage of the amphiphilicity of the PCs.

\section{Materials and Methods}

\subsection{Materials}

Cod liver oil was donated by Vesteraalens A/S (Sortland, Norway) and kept at $-40^{\circ} \mathrm{C}$ until use. Peroxide value of the cod liver oil was $0.09 \pm 0.00$ meq peroxides $/ \mathrm{kg}$ oil. The fatty acid content of the fish oil (\%, w/w) was as follows: C14:0 (4.0), C16:0 (9.2), C16:1 n-7 (8.3), C18:0 (2.2), C18:1 n-9 (15.8), C18:1 n-7 (4.1), C18:2 n-6 (2.5), C18:3 n-3 (0.2), C20:1 n-9 (11.4), C20:5 n-3 (8.8), C22:1 n-11 (5.4), and C22:6 n-3 (11.4). Alpha-, beta-, gamma-, and 
126 caseinate (Miprodan 30) was provided by Arla Foods Ingredients amba (Viby J, Denmark).

127 Protein content of the sodium caseinate was reported as $92 \%$ by Arla.

128 Phosphatidylcholine extracted from soybean (LIPOID S100, soy PC) was donated by Lipoid

$129 \mathrm{GmbH}$, Germany. Peroxide value of phosphatidylcholine was 1.91 meq peroxides $/ \mathrm{kg}$ sample.

130 It was reported in the analysis of certificate of the LIPOID S100 that $97.1 \%$ of the product was

131 phosphatidylcholine (based on dry weight) and contained $0.20 \%$ DL- $\alpha$-Tocopherol, which is

132 an antioxidant. Other lipid molecules were also reported as follows: $1.2 \%$

133 lysophosphatidylcholine, $\quad 0.5 \% \quad \mathrm{~N}$-acyl-phosphatidylethanolamine, $\quad \leq 0.1 \%$

134 phosphatidylethanolamine, $\leq 0.1 \%$ phosphatidylinositol, $0.8 \%$ non-polar lipids, and $0.3 \%$

135 triglycerides. The fatty acid (\%,w/w) content of the soy PC (LIPOID S100) was analyzed and

136 found as follows: C14:0 (0.09), C16:0 (12.55), C18:0 (3.77), C18:1 n-9 (8.42), C18:2 n-6

137 (65.82), C18:3 n-6 (7.11). Caffeic acid was purchased from Sigma Aldrich. Modified PCs

138 (PC_C14 and PC_C16) with different alkyl chains C14 or C16 and caffeic acid were

139 synthesized as described in a previous study (Anankanbil et al., 2018). The fatty acid content

140 (\%,w/w) of PC_C14 and PC_C16 were C14:0 (99.38\%) and C16:0 (98.74\%), respectively. All

141 solvents and chemicals used were of analytical grade.

\subsection{Experimental design}

143 Table 1 shows the sample codes, descriptions and amounts of ingredients. All emulsion 144 samples include $70 \% \mathrm{w} / \mathrm{w}$ fish oil and $2.8 \% \mathrm{w} / \mathrm{w}$ total emulsifier with a $1.2 \mathrm{CAS}$ : total PC ratio.

145 These values were determined based on a previous study (Yesiltas et al., 2019). Soy PC was 146 replaced by modified PCs in order to obtain various final caffeic acid concentrations, namely 
147360,1080 and $2160 \mathrm{ppm}$ in the final emulsion. Emulsions produced with soy PC and free 148 caffeic acid were included as controls.

\subsection{Emulsion preparation, storage and sampling}

151 Aqueous phases were prepared by dissolving emulsifiers (CAS, PC, and modified PCs) in 152 distilled water and stirred overnight at $4^{\circ} \mathrm{C}$. Before emulsification, aqueous phases were 153 adjusted to $\mathrm{pH} 7$ using $2 \mathrm{M} \mathrm{NaOH}$. Emulsions were produced in $500 \mathrm{~g}$ batches using a 154 Stephan Universal mixer (Stephan, UMC5, 1995, Hameln, Germany) as described by Horn et 155 156 separated at the bottom of the bottle. Creaming index was presented as in percentage. 
168 The dynamic interfacial tension of the emulsifiers at the oil-water interface was determined using an automated drop tensiometer OCA20 (DataPhysics Instruments GmbH, Filderstadt,

170 Germany) at $25^{\circ} \mathrm{C}$. Aqueous phases of emulsions 1 CAS, 2 PC_com, 5 PC_C14_2160 and 8 171 PC_C16_2160 (codes explained in Table 1) were prepared as described before and 172 measured in duplicates. The surfactant solution (aqueous phase) was filled into a syringe with 173 a screwed needle. For each measurement, a small drop of the aqueous phase sample 174

$\Delta \mathrm{P}=\gamma\left(\frac{1}{R_{1}}+\frac{1}{R_{2}}\right)$

(Equation 2)

where $\Delta P\left(\mathrm{mN} / \mathrm{m}^{2}\right)$ is the pressure difference across the interface, $\mathrm{V}(\mathrm{mN} / \mathrm{m})$ is the interfacial tension and $R_{1}$ and $R_{2}(m)$ are the principal radii of curvature of the pendant drop. Measurements were carried out in duplicate. Changes in the interfacial tension $(\mathrm{mN} / \mathrm{m})$ were plotted as a function of time ( $\min )$ for each aqueous phase solution.

186 Particle size of the emulsions was performed using laser diffraction in a Mastersizer 2000 187

\subsubsection{Droplet size}

(Malvern Instruments, Ltd., Worcestershire, UK) on days 0 and 12 according to the method described by Horn et al. (2011). Results were calculated as the surface weighted (D[3,2]) and 
189 volume weighted (D[4,3]) mean diameter, which were calculated based on the equations 3 190 and 4, respectively:

$191 \quad D[3,2]=\Sigma n_{i} d_{i}^{3} / \Sigma n_{i} d_{i}^{2}$

(Equation 3)

$192 \quad \mathrm{D}[4,3]=\Sigma n_{i} d_{i}^{4} / \Sigma n_{i} d_{i}^{3}$

(Equation 4)

193

where $\mathrm{n}$ is the number of droplets with a specific diameter, $\mathrm{d}$ is the diameter of the droplet and, i represents the size class of the droplets. Samples were measured in duplicates.

\subsubsection{Relative protein content in the aqueous phase and the surface load of} proteins

Protein content of the aqueous phase was determined based on the method described by Jacobsen, Meyer, \& Adler-Nissen (1998). Emulsion sample ( 20 g) was centrifuged for 10 min at 25,400g and $10^{\circ} \mathrm{C}$ (Sorvall RC-6 PLUS, Thermo Fisher Scientific, Osterode, Germany; rotor SS-34) to separate the aqueous phase and oil phase. Supernatant (oil phase) was removed by the use of a pipette. The rest was mixed with distilled water (1:1) and then subjected to ultracentrifugation (Beckman Ultracentrifuge L8-60M, Fullerton, CA; rotor 21102) for $1 \mathrm{~h}$ at $106,979 \mathrm{~g}$ and $15^{\circ} \mathrm{C}$. Protein content of the aqueous phase was determined by the Dumas method (Elementar, Mt. Laurel, NJ, USA). Approximately $1 \mathrm{~g}$ of aqueous phase was placed in the sample tray and further steps were automated including sample combustion in a chamber at a high temperature $\left(900^{\circ} \mathrm{C}\right)$ in the presence of oxygen. Content of crude protein was estimated by using a conversion factor (6.25). Protein content (g) was calculated in the aqueous phase. Measurements were performed in duplicate. 
209 The surface load of proteins $\left(\Gamma, \mathrm{mg} / \mathrm{m}^{2}\right)$ was calculated according to the equation described 210 by Zhu et al. (2018), equation 5:

$211 \Gamma=\frac{V c\left(C_{I N I}-C_{S E R}\right)}{S V_{O L L}}=\frac{(1-\Phi) d_{32}}{6 \Phi}\left(C_{I N I}-C_{S E R}\right)$

212 where $\mathrm{V}_{\mathrm{C}}$ and $\mathrm{V}_{\mathrm{OIL}}$ are the volume of the aqueous and oil phase $(\mathrm{mL}), \mathrm{S}$ is the surface area of

213 the emulsion droplets $\left(\mathrm{m}^{2}\right), \Phi$ is the oil phase volume fraction, $\mathrm{C}_{\mathbb{I N I}}$ is the initial concentration

214 of the protein in the aqueous phase $(\mathrm{mg} / \mathrm{L})$, and $\mathrm{C}_{\mathrm{SER}}$ is the non-adsorbed protein 215 concentration in the aqueous phase after emulsification $(\mathrm{mg} / \mathrm{L})$.

\subsubsection{Zeta potential}

217 Zeta potential measurements were carried out using Zetasizer Nano 2S (Malvern 218 Instruments, Ltd.) in order to determine the surface charge of the emulsion droplets. Samples 219 were prepared by diluting emulsion samples in distilled water $(0.32 \mathrm{~g}$ emulsion $+40 \mathrm{~g}$ of 220 distilled water) and vortexed before measurement. Samples were placed in DTS-1070 221 disposable folded capillary cell (Malvern Instruments, Ltd., United Kingdom). The zeta 222 potential range was set to -100 to $+50 \mathrm{mV}$ and measurements were done at $25^{\circ} \mathrm{C}$ on the 223 samples collected on day 2. Measurements were done in duplicates.

\subsubsection{Apparent viscosity}

Apparent viscosity was determined with a stress-controlled rheometer (Stresstech, Reologica Instruments $A B$, Lund, Sweden) on days 1 and 12. CC25 standard bob cup system in a

227 temperature vessel was used in order to perform the measurements. Emulsions (15 ml) were 228 measured over a shear stress range from 0.0125 to $50 \mathrm{~Pa}$ at $25^{\circ} \mathrm{C}$. Results were calculated 
229 on a specific shear rate $\left(20 \mathrm{~s}^{-1}\right)$ for each emulsion in Pascal second (Pa.s). Samples were 230 measured in duplicate.

\subsection{Methods for lipid oxidation measurements of emulsions}

\subsubsection{Primary oxidation products-peroxide value (PV)}

Primary oxidation products were determined according to the Bligh and Dyer method with

slight changes (Bligh \& Dyer, 1959). Lipids were extracted using $5 \mathrm{~g}$ of emulsion and a

reduced amount of solvent $(30.0 \mathrm{~mL}$ of methanol and chloroform, 1:1). PV was subsequently

determined on the lipid extracts by colorimetric determination of iron thiocyanate on a spectrophotometer (Shimadzu, UV mini 1240, Kyoto, Japan) at $500 \mathrm{~nm}$ (Shantha and Decker, 1994). Measurements were done in duplicates.

Tocopherol content of emulsions was analyzed by HPLC (Agilent 1100 Series; Column:

Waters Spherisorb $3 \mu \mathrm{m}$ Silica; 4.6×150 mm). Tocopherol analysis was performed according to the official AOCS method (1998) using lipid extracts (Section 2.5.1), which were further evaporated and dissolved in heptane. Measurements were carried out in duplicates.

\subsubsection{Secondary oxidation products—Dynamic Head Space GC-MS}

Volatile secondary oxidation products were analyzed according to the method described by Yesiltas et al (2018a). Volatile compounds were trapped on Tenax GR tubes. The volatile compounds were separated in a gas chromatograph (Agilent Technologies, 6890N Network 
249 film thickness; Agilent Technologies, J\&W GC Columns, CA, USA). Mass-spectrometry 250 (Agilent 5973 Network Mass Selective Detector, Agilent Technologies, $70 \mathrm{eV}$; mass to charge 251 ratio scan between 30 and 250) was used to analyze individual volatile compounds and MS252 library searches (Wiley $138 \mathrm{~K}$, John Wiley and Sons, Hewlett-Packard) was used for the 253 identification. The volatile compounds 2-ethyl-furan, 1-penten-3-one, 1-penten-3-ol, (E)-2254 pentenal, hexanal, (E)-2-hexenal, (Z)-4-heptenal, 2-pentyl-furan, (E)-2-heptenal, 255 benzaldehyde, (E,E)-2,4-heptadienal, nonanal and (E,Z)-2,6-nonadienal were analyzed in 256 emulsion samples.

\subsection{Statistical analysis and principle component analysis (PCA)}

258

259

260

261

262

263

264

265

266

267

268

269

Statgraphics XVII (Statpoint Technologies, Inc., Virginia, USA) was used to carry out the analysis of variance (ANOVA) using Fisher's least significant difference test. The significance was evaluated statistically at the confidence level $1-\alpha=95 \%$.

PCA was performed using Latentix 2.12 (LatentiX, Copenhagen, Denmark). It was carried out with the emulsions as objects and creaming, droplet size, zeta potential, viscosity, peroxide value, alpha-tocopherol, and volatile compounds as variables. The data was transformed using the autoscale function in Latentix and the PCA models were calculated.

\section{Results and Discussion}

\subsection{PCA of all emulsions}

Two different PCA models were calculated; one where all time points for each of the variables were included and one where only the last time point (day 12) of the variables was included. The conclusion that could be made from these 2 models was more or less the same. For the 
270 sake of simplicity, only the model calculated with the last time point for the variables is shown

271 in Fig. 1. The first principle component (PC1) and second principle component (PC2)

272 explained 43 and $29 \%$ of the variation in the data, respectively. The scores plot showed that

273 the 1_CAS emulsion located differently compared to the rest of the emulsions, indicating that

274 it behaved differently with respect to the physical and oxidative parameters measured. The

275 loadings plot showed that the location of CAS was mostly explained by the high viscosity as

276 well as higher protein content in the aqueous phase (non-adsorbed CAS). Oxidation

277 parameters, PV, tocopherols and volatile compounds were located in the same quadrant and

278 correlated with the following emulsions: 2_PC_com, 3_PC_C14_360, 6_PC_C16_360, and

279 9_PC_com_caf_360, which were most prone to lipid oxidation.

280 Emulsion 10_PC_com_caf_2160 was mostly explained by less negative zeta potential, high 281 creaming, low viscosity and low non-adsorbed proteins. Emulsions produced with middle and 282 high concentrations of modified PCs were not described specifically by any of these physical parameters. However, they located far from the oxidative parameters, which indicated that 284 their oxidative stability were superior compared to the rest. In order to obtain a better overall picture of the emulsions according to the physical parameters, see the biplot (Supplementary 286 Fig. 2) for the PCA model calculated only with physical parameters.

287 It was observed that the emulsions with PC_C14 were closer to viscosity and non-adsorbed CAS compared to PC_C16, whereas emulsions with PC_C16 located closer to zeta potential and creaming. This indicated differences in physical stability. Thus, emulsions containing PC_C14 had higher viscosity, which might be due to the higher amount of non-adsorbed CAS 
292 protein surface load, creaming, and lower negative zeta potential. Moreover, the oxidation parameters showed that the emulsions with PC_C14 located closer to oxidation parameters 294 (volatiles, PV) compared to PC_C16 emulsions, which confirmed better oxidative stability of 295 the emulsions produced with PC_C16. In order to confirm this interpretation of the PCA 296 model, the original raw data of the physical and oxidative stability parameters were studied in more detail.

\subsection{Characterization of emulsions}

\subsubsection{Creaming Index}

Emulsions produced with the combinations of CAS and soy PC were creamed $4-6 \%$, whereas emulsions produced with only CAS did not have any creaming during 12 days of storage (Supplementary Fig. 3a,b). Modified emulsifiers also showed between 2-4\% creaming during 12 days of storage. As these emulsions have lower creaming rate than $1 \mathrm{~mm} /$ day, they were all considered as stable emulsions (McClements, 1999).

\subsubsection{Interfacial tension of the emulsifier combinations}

Oil-water interfacial tension of the aqueous phase of the emulsions was measured in order to determine the effects of substituting $45 \%$ of the CAS with different PCs. The interfacial tension values of all the samples at 15 min were significantly different from each other $(p<0.05)$. It was observed that 2_PC_com had an oil-water interfacial tension of $11.47 \pm 0.35$ $\mathrm{mN} / \mathrm{m}$, whereas aqueous phase of 1 CAS had an interfacial tension of $8.34 \pm 0.02 \mathrm{mN} / \mathrm{m}$ (Fig. 2). Thus, including soy PC increased the interfacial tension. However, when $60 \%$ of the soy PC in 2_PC_com was substituted with PC_C14 or PC_16, interfacial tension dropped 
313 significantly from $11.47 \pm 0.35 \mathrm{mN} / \mathrm{m}$ to $4.57 \pm 0.01$ or $3.94 \pm 0.04 \mathrm{mN} / \mathrm{m}$, respectively. Thus,

314 although both commercial and modified PC's could self-assemble in the aqueous phase and

315 form micelles, significant differences in interfacial tension values were observed between the

316 different emulsifier combinations. Aqueous phases with PC_C16 showed significantly lower

317 interfacial tension compared to PC_C14, which could be due to the interaction of PC_C16

318 with soy PC and CAS at the interface as well as higher affinity to the oil phase. Low interfacial 319 tension provided by modified PCs implies a superior surface activity, which provided 320 minimized contact area between hydrophobic and hydrophilic regions.

\subsubsection{Droplet size}

322 The mean particle diameter $(\mathrm{D}[4,3])$ of the emulsions was determined in order to observe the impact of emulsifier types and different concentrations of modified PCs (Table 2). Substituting $45 \%$ of CAS with soy PC resulted in a significant increase in droplet size from $8.8 \pm 0.3$ to 17 $325 \pm 0.2 \mu \mathrm{m}$. However, increasing concentration of modified PCs in the emulsions led to a significant decrease in droplet size (Table 2). This could be due to the fact that modified PCs had one alkyl chain instead of 2 alkyl chains compared to soy PC as well as a larger head part as a result of covalently attached caffeic acid in the glycerol backbone, which might have enhanced the surface activity. This was valid for both PC_C14 and PC_C16, which could be attributed to their fast adsorption rates compared to proteins and soy PC, thereby producing smaller oil droplets by inhibiting droplet coalescence during homogenization. Improved performance of lysolecithins compared to conventional PC with 2 fatty acid chains was reported previously by other researchers (Choi et al., 2011; Casado, Martin, Torres, \&

334 Reglero, 2012). This could be due to higher HLB values of modified PCs compared to 
335 conventional PC $(\mathrm{HLB}=8)$, which provides higher surface activity and better stabilizing ability

336 in oil-in-water emulsions. It has been emphasized that lysolecithins usually disperse better in

337 the aqueous phase which influence their effectiveness (McClements et al, 2017).

338 When the droplet size of the emulsions with the equivalent concentrations of modified PCs 339 was compared, it was observed that PC_C14 provided smaller droplets compared to PC_C16, which indicated faster adsorption of PC_C14 at the oil-water interface compared to PC_C16 at their middle and higher concentrations. At the low concentration of modified PCs, there was no significant effect of chain length observed for droplet sizes.

These results are generally consistent with the interfacial tension results, for which it was found that the aqueous phase of 2_PC_com had higher oil-water interfacial tension compared to 1_CAS, whereas addition of modified PCs decreased the interfacial tension significantly. Higher surface activity of modified PCs improved emulsification of smaller droplets before their coalescence. Moreover, it was obvious that the increasing concentration of modified PCs provided significant decrease in droplet size (Table 2). The change in the droplet size with increased concentration of modified PCs can also be seen in the optical microscope images

350 (Supplementary Fig. 4a,b). There was no significant increase in D[4,3] droplet sizes observed 351 during storage except for 5_PC_C14_2160 (Table 2, Supplementary Fig. 5a).

\subsubsection{Protein content in the aqueous phase and the surface load of proteins}

353 Protein content in the aqueous phase has several effects on physical and oxidative stability of 354 the emulsions. A previous study showed that viscosity of the emulsions was directly increased 355 by the concentration of CAS in the continuous water phase when the concentration was 
356 between $5-10 \%$ in $30 \%$ oil-in-water emulsion (Liang et al., 2014). Viscosity of the final

357 emulsion increases with the increasing viscosity of the continuous water phase (Tesch \&

358 Schubert, 2002; Yesiltas et al., 2018a). It was observed that the protein content in the water

359 phase was around 2-fold higher for emulsion produced with only CAS compared to the rest of

360 the emulsions, which might explain the significantly higher viscosity of the CAS emulsion

361 (Table 1). On the other hand, proteins (e.g., CAS) inhibit oxidation due to their radical

362 scavenging and metal chelating activities, which allow proteins to deactivate prooxidants

363 either at the oil-water interface or in the aqueous phase (Faraji, McClements, \& Decker, 2004;

364 Berton, Ropers, Viau, \& Genot, 2011). For these reasons, we have determined the protein

365 content in the aqueous phases of the emulsions. Additionally, we have calculated the protein

366 surface load in order to indirectly infer the adsorption of modified PCs at the interface. Forty to

$36766 \%$ of the protein was non-adsorbed in the aqueous phase, which indicated that the proteins

368 were available in the aqueous phase in concentrations ranging between $2.25-6.23 \mathrm{wt} \%$.

369 Non-adsorbed protein of 8_PC_C16_2160 was significantly lower compared to the rest of the

370 emulsions except for 6_PC_C16_1080 and 7_PC_C16_2160 (Table 2). Changing modified

371 PC concentration did not affect the protein content in the aqueous phase significantly neither

372 for PC_C14 nor PC_C16. Given that 5_PC_C14_2160 had significantly more protein content

373 in the water phase compared to 8_PC_C16_2160,PC_C14 showed better surface activity at

374 the oil-water interface, thereby replacing more protein at the oil-water interface. Protein

375 surface load results revealed more information about the adsorbed protein due to the impact

376 of droplet size on the protein surface load. Interestingly, involvement of soy PC led to 4 folds

377 higher protein load at the oil-water interface compared to 1_CAS (see 1_CAS versus

378 2_PC_com, 9_PC_com_caf_360, and 10_PC_com_caf_2160, Table 2). This could be due to 
379 the interaction between CAS and soy PC, which presumably resulted in the adsorption of larger CAS aggregates and PC multilayers at the interface. This hypothesis was supported by results from another study from our lab, which indicated that emulsions produced with CAS and PC provided thicker interface layer compared to only CAS emulsions and which provided a model for the complex structure of $70 \%$ oil-in-water emulsions with CAS and PC as emulsifiers (data submitted for publication). Protein surface load decreased with increasing concentration of modified PCs both for PC_C14 and PC_C16 (Table 2). Emulsions with PC_C14 had lower protein surface load compared to emulsions with PC_C16, which would 387 normally support that PC_C14 was more surface active and replaced more proteins at the 388 interface compared to PC_C16. However, interfacial tension results (Section 3.1.2) indicated that aqueous phase with PC_C16 had lower interfacial tension $(4 \mathrm{mN} / \mathrm{m})$ compared to 390 PC_C14 $(5 \mathrm{mN} / \mathrm{m})$. This was presumably due to PC_C16`s more balanced molecular interactions with soy PC and CAS at the interface, such as forming a densely packed 392 interfacial layer with less permeability, which are not merely related to the surface activity of the molecule. Therefore, these results could be attributed to thicker oil-water interfacial layer 394 formed in the presence of PC_C16, which thereby led to a higher protein surface load 395 compared to PC_C14.

All the samples had negative zeta potential, which was mainly attributed to the CAS being 398 above its isoelectric point $(\mathrm{pH} 4.6)$ as the $\mathrm{pH}$ of the emulsion was 7 (O'Kennedy, 2011) (Table 399 2). Soy PC is a zwitterionic molecule, but it generally gives negative surface charge at neutral conditions (Anankanbil et al., 2018). Modified PCs were also negatively charged due to the 
401 phosphate groups at $\mathrm{pH}$ 7. Thus, when these emulsifiers were used alone to emulsify $20 \%$ 402 fish oil-in-water emulsions at $\mathrm{pH} 7$, they resulted in a surface charge of $-37.2 \pm 0.2,-39.5 \pm$ 4030.1 and $-50.2 \pm 0.1 \mathrm{mV}$ for PC_C14, PC_C16 and soy PC, respectively (Anankanbil et al., 404 2018). In the current study, it was observed that the substitution of some of the CAS with soy 405 PC or soy PC + modified PCs resulted in less negatively charged lipid droplets.

Free caffeic acid addition did not result in any significant change in surface charge of the 407 emulsions produced with CAS and soy PC (Table 2). Increasing the concentration of modified 408 PCs did not have a clear effect on surface charge. Comparison of the surface charge of the emulsions produced with equivalent concentrations (360 and $1080 \mathrm{ppm}$ caffeic acid) of 410 modified PCs showed that the emulsions with PC_C14 provided more negatively charged particles compared to PC_C16. The determination of the protein content in the aqueous 412 phase and protein load at the interface showed that PC_16 interacted more with CAS and soy PC at the oil-water interface compared to PC_C14. Since CAS is more negatively charged 414 than modified PCs, one would expect that the PC_16 emulsions would have a more negative 415 charge than the emulsion with PC_14. However, adsorption of these emulsifiers does not necessarily result in a monolayer. The overall zeta potential of the oil droplets will be affected

417 by all the emulsifiers involved, e.g., CAS, commercial PC and modified PC as well as their conformation at the oil-water interface depending on their interactions, which might not lead to a straight forward correlation between zeta potential results and emulsifiers used. Therefore, protein surface load results indicated that the interaction between CAS, soy PC and PC_C16 resulted in a thicker interfacial layer, which gave less negative zeta potential due to the higher amount of PC_C16 compared to the amount of PC_C14 when involved in the emulsions. 
423 The reason for less negatively charged droplet surfaces for 2_PC_com compared to 424 3_PC_C14_360 and more negatively charged than 7_PC_C16_1080 could also be attributed 425 to higher amount of CAS, soy PC and PC_C16 adsorbed at the oil-water interface and the 426 interaction between emulsifiers forming a thicker interface. Moreover, as there was no 427 significant difference in protein surface load of emulsions produced with PC_C14 and 428 PC_C16 at their equivalent concentrations, different surface charge could be attributed to the 429 content of soy PC and modified PCs. As emulsions with PC_C16 had less negative zeta 430 potential, this indicates the presence of higher amount of soy PC and PC_C16 at the oil-water 431 interface compared to emulsions produced with PC_C14.

\subsubsection{Apparent viscosity}

433 Emulsions were non-Newtonian and showed shear thinning behavior. Substitution of $45 \%$ of 434 the CAS with soy PC decreased viscosity significantly as expected due to the increase in 435 droplet size (D[4,3], Table 2). Viscosity of the emulsions decreased significantly during 436 storage except for 1_CAS and 9_PC_com_caf_360 (Table 2, Supplementary Fig. 5b). 437 Addition of $2160 \mathrm{ppm}$ free caffeic acid into the CAS + soy PC emulsions resulted in significant 438 decrease in the viscosity as well, which correlated well with the significant increase in the 439 droplet size (D[4,3], Table 2). This negative correlation between droplet size and viscosity 440 could be due to smaller droplets leading to more friction between oil droplets at an expanded 441 surface-to-volume ratio of the dispersed phase. This results in less mobility of the droplets in 442 the emulsion and therefore provides higher viscosity compared to emulsions having larger 443 droplets (Yesiltas et al., 2019). Similar observations regarding decrease in viscosity with the 
444 addition of caffeic acid were made for $70 \%$ fish oil-in-water emulsions produced with CAS and 445 diacetyl tartaric acid esters of mono- and diglycerides (DATEM) (Yesiltas et al., 2018b).

446 On the other hand, this argument was not valid when looking at the effects of increased 447 modified PCs concentration on viscosity. It was observed that the viscosity did not necessarily 448 increase with decreasing droplet size. This could be due to the effect of protein content in the 449 aqueous phase. As discussed in section 3.1.4, protein content in the aqueous phase might 450 increase the viscosity of the final emulsion when proteins are present in higher 451 concentrations. The concentration of CAS in the aqueous phase (2.25 - 6.23 wt \%, Table 2) 452 might have affected the viscosity of the emulsions with modified PCs at their highest and 453 middle concentrations; 4_PC_C14_1080 and 5_PC_C14_2160 had significantly higher 454 viscosity compared to 7_PC_C16_1080 and 8_PC_C16_2160, respectively, whereas this was 455 not the case for the lower concentrations of modified PCs (3_PC_C14_360 and 456 6_PC_C16_360).

\subsection{Oxidative stability of emulsions}

\subsubsection{Primary oxidation products - peroxide value}

459 Lipid hydroperoxides were analyzed to compare the oxidation rate of the emulsions during 12 460 days of storage (Fig. 3). As expected the use of modified PCs' had an impact on the oxidative 461 stability of high fat fish oil-in-water emulsions. Peroxide value (PV) of 1_CAS was lower 462 compared to 2_PC_com, which showed that substitution of $45 \%$ of the CAS with soy PC did not improve the oxidative stability of the $70 \%$ fish oil-in-water emulsion in terms of primary 464 oxidation products. The addition of modified PCs low concentrations (see 3_PC_C14_360 
465 and 6_PC_C16_360, in Fig. 3) resulted in prooxidant effect when compared to 2_PC_com.

466 Emulsions containing modified PCs had higher PV than CAS + soy PC emulsions, which

467 contained the equivalent amount of caffeic acid but in free form. Thus, the use of modified PC

468 with caffeic acid attached did not reduce the formation of hydroperoxides when added both at 469 low and high concentrations. The beneficial effect of having free caffeic acid in the aqueous 470 phase compared to having caffeic acid covalently attached to the PC could be due to the 471 enhanced ability of free caffeic acid in binding iron in the aqueous phase, which limits metal 472 catalyzed initiation and free radical formation (Frankel, 2012a).

473 Emulsions with PC_C16 had higher PV compared to emulsions with equivalent amount of 474 PC_C14. This could be explained by the faster degradation of hydroperoxides in emulsions 475 with PC_C14 (see section 3.3.3).

\subsubsection{Changes in tocopherol content}

477 Alpha-, gamma-, and delta-tocopherol levels in emulsions were in the range of $105.7 \pm 0.7-$ $478 \quad 133.6 \pm 3.7,72.1 \pm 0.1-74.2 \pm 0.7,29.1 \pm 0.7-30.5 \pm 0.3 \mu \mathrm{g}$ toc $/ \mathrm{g}$ emulsion at day 0 479 (Supplementary Fig. 6a-c). As the fish oil content was the same in all emulsions, significant 480 differences between tocopherol contents in emulsions were attributed to the consumption of 481 tocopherol during emulsion production at day 0. Emulsion 1_CAS had significantly higher 482 consumption of all types of tocopherols compared to 2_PC_com. When the soy PC was 483 substituted with increasing concentration of modified PCs, alpha tocopherol content 484 decreased significantly, which indicated that the alpha-tocopherols were acting as 485 antioxidants in the presence of modified PCs or there was an interaction between modified 
486 PCs and alpha-tocopherols during emulsification. Free caffeic acid addition did not have any 487 significant effect on any tocopherols in the emulsions produced with CAS and soy PC, which 488 indicated that the alpha-tocopherol content was not affected by the presence of free caffeic 489 acid at day 0.

490 The changes in the tocopherol content were followed during 12 days of storage and it was 491 found that the alpha-tocopherol content decreased significantly only for 5_PC_C14_2160 and 492 8_PC_C16_2160, whereas gamma-tocopherol decreased significantly for 5_PC_C14_2160, 493 8_PC_C16_2160, and 10_PC_com_caf_2160 (Supplementary Fig. 6a,c). There was no 494 significant decrease in delta-tocopherol content of the emulsions during 12 days of storage. 495 These results indicated that the total tocopherol content of the emulsions with the highest 496 concentration of caffeic acid decreased significantly, which showed that part of the antioxidant 497 activity was due to tocopherols in these emulsions. However, the decrease in the amount of 498 tocopherol from day 0 to 12 was only around $5 \mu \mathrm{g}$ toc/g sample. It should also be considered 499 that alpha-tocopherols can be regenerated from oxidized tocopherol (e.g., tocopherol 500 quinone) with the proton-donating capacity of the amino group of phospholipids such as 501 phosphatidylethanolamine, phosphatidylserine, and phosphatidylcholine (García-Moreno et 502

al., 2014; Samdani, McClements, \& Decker, 2018). Therefore, the antioxidant activity of alpha-tocopherol could be even higher than what was measured due to its possible consumption and regeneration.

\subsubsection{Secondary volatile oxidation products - DHS GC-MS}


506 Volatile oxidation products formed in the emulsions showed similar trend in terms of their

507 content during 12 days of storage; therefore, sum of the volatiles was presented in Fig. 4.

508 Development of 1-penten-3-ol, (E,E)-2,4-heptadienal, 2-pentenal, and 2-ethylfuran, which 509 were in high concentration compared to rest of the volatile compounds, are also shown in

510 Supplementary Fig. 7a-d. It was observed that 360 ppm caffeic acid provided with modified

511 PCs resulted in a prooxidant effect. On the contrary, physical mixture of caffeic acid and PC

512 (9_PC_com_caf_360) did not cause a prooxidant effect, when compared to 2_PC_com.

513 For both modified PCs, oxidative stability was improved with the increasing amount of

514 modified PCs. All emulsions with modified PC added in concentrations above $360 \mathrm{mg} / \mathrm{kg}$ had 515 lower formation of volatile oxidation products than the emulsion with commercial PC as also

516 observed in the PCA plot. Improved oxidative stability of emulsions with modified PCs could

517 be due to the fact that caffeic acid was located at the interface showing antioxidant activity. It

518 could also be due to the larger surfactant head group of modified PCs compared to soy PC,

519 which led to thicker oil-water interfacial layer (Berton-Carabin et al., 2014).

520 Emulsion 8_PC_C16_2160 had better oxidative stability compared to 10_PC_com_caf_2160, 521 which showed that caffeic acid in high concentrations was more efficient when attached to

522 PC_16 than when present in its free form. This could be attributed to different interface 523 structure and composition of the emulsions due to the molecular structure differences

524 between PC and PC_16, which affects the adsorption performance of the molecules and the 525 location of caffeic acid. It is worth paying attention to the significant differences in physical 526 properties of these two emulsions such as droplet size. There has been contradicting results 527 on the impact of droplet size on oxidative stability (Berton-Carabin et al., 2014). Nevertheless, 
528 studies which have shown an impact of droplet size have found that small droplets increase

529 lipid oxidation. Hence, the large droplets in the soy PC emulsions would favor decreased 530 oxidation and not increased oxidation as observed here.

531 Results also showed that on the last day of storage, CAS emulsion had higher concentrations 532 of volatile compound than emulsions with PC_C14_2160, PC_C16_1080 and PC_C16_2160 533 ppm.

534 On the other hand, PC_C16 had a lower amount of volatile compounds formed compared to 535 PC_C14 in all concentrations of added modified PCs (Fig. 3), which could be attributed to the 536 interface structure of the emulsions. This could be explained by the interfacial tension results 537 discussed under the section 3.2.2, where PC_C16 was indicated to have a better interaction 538 with CAS and soy PC, thereby forming a thicker interface, higher packing density and less permeability at the oil-water interface compared to PC_C14 (McClements and Decker, 2018).

540 Moreover, as it was discussed in the section 3.2.4, PC_C16 had lower amount of non541 adsorbed protein in the aqueous phase compared to PC_C14 at their highest concentration, 542 thereby higher protein surface load, which supported the formation of a thicker interfacial 543 layer for PC_C16 and a better coverage of the oil droplets compared to PC_C14. Higher 544 amount of emulsifiers at the oil-water interface inhibited prooxidant diffusion from aqueous 545 phase to oil phase and brought antioxidant activity (due to the presence of antioxidant 546 emulsifiers) to the interface, thereby increasing oxidative stability.

547 Another reason for higher oxidative stability could be attributed to the diffusion of some of the 548 PC_C16 into the oil phase in low concentrations (e.g., below its critical micelle concentration), 
549 due to its high hydrophobicity and thereby acting as a chain-breaking antioxidant in the oil

550 phase. Individual PC_C16 molecules might act as an antioxidant owing to the covalently

551 attached caffeic acid on the head group of the molecule and thereby contribute to the overall

552 increased oxidative stability of the emulsions with PC_C16. Besides, both modified PCs could

553 also have potential hydrophobic interactions with emulsifiers or aggregates in the aqueous

554 phase, which might have improved their antioxidative effects (Shahidi and Zhong, 2011).

\section{4. Conclusion}

556 Soy and modified PCs in combination with CAS, as emulsifiers, decreased the viscosity of

$55770 \%$ omega-3 delivery emulsions compared to emulsions stabilized with only CAS. This

558 suggests that the emulsions can potentially be used in wider range of applications in food 559 systems when higher amount of omega-3 polyunsaturated fatty acids are needed. The use of 560 soy PC in combination with CAS decreased physical stability. However, the physical stability 561 was significantly improved when soy PC was partly replaced by modified PCs with C14 or

562 C16 alkyl chain as well as covalently attached caffeic acid due to their high surface activity.

563 The highest oxidative stability was observed for the emulsion with the highest concentration of 564 modified PC with C16 alkyl chain length and covalently attached caffeic acid. This was 565 attributed to its low interfacial tension and ability to interact with CAS and soy PC, which led to 566 thicker interfacial layer and less permeability for prooxidants, thereby resulting in better 567 oxidative stability.

\section{Abbreviations used}

569 CAS - sodium caseinate 
570 DHA - docosohexaenoic acid

571 DHS - dynamic head space

572 EPA - eicosapentaenoic acid

573 LC n-3 PUFAs - Long chain omega-3 polyunsaturated fatty acid

574 PC - phosphatidylcholine

575 PC_C14 - modified PC with covalently attached caffeic acid and C14 alkyl chain

576 PC_C16 - modified PC with covalently attached caffeic acid and C16 alkyl chain

577 PCA - principle component analysis

$578 \quad$ PV - peroxide value

\section{Acknowledgements}

580 We would like to thank Lipoid $\mathrm{GmbH}$, Arla Foods Ingredients amba and Maritex A/S Norway 581 for donating phosphatidylcholine, sodium caseinate and cod liver fish oil, respectively. 582 Furthermore, we are grateful to Lis Berner for her skillful work in the laboratory. We are 583 thankful to Terje Svingen for giving the instructions for taking microscopy images. Finally, we 584 would like to thank the Danish Council for Independent Research Technology and Production 585 Sciences for financing the project Mapping and Characterizing of Lipid Oxidation in Emulsified 586 Systems (MAPOX, DFF-4184-0123A). 


\section{References}

589 Alemán, M., Bou, R., Guardiola, F., Durand, E., Villeneuve, P., Jacobsen, C., \& Sørensen, A.590 D. M. (2015). Antioxidative effect of lipophilized caffeic acid in fish oil enriched mayonnaise 591 and milk. Food Chemistry, 167, 236-244.

592 Anankanbil, S., Pérez, B., Banerjee, C., \& Guo, Z. (2018). New phenophospholipids equipped 593 with multi-functionalities: Regiospecific synthesis and characterization. Journal of Colloid and 594 Interface Science, 523, 169-178.

595 AOCS Official Method Ce 8-89 (1998). Determination of tocopherols and tocotrienols in 596 vegetable oils and fats by HPLC. Champaign, IL, USA: AOCS.

597 Berton, C., Ropers, M. H., Viau, M., \& Genot, C. (2011). Contribution of the interfacial layer to 598 the protection of emulsified lipids against oxidation. Journal of Agricultural and Food 599 Chemistry, 59, 5052-5061.

600 Berton-Carabin, C. C., Ropers, M., \& Genot, C. (2014). Lipid oxidation in oil-in-water 601 emulsions: Involvement of the interfacial layer. Comprehensive Reviews in Food Science and 602 Food Safety, 13, 945-977.

603 Berton-Carabin, C. C., Sagis, L., \& Schroën, K.. (2018). Formation, Structure, and 604 Functionality of Interfacial Layers in Food Emulsions. Annual Review of Food Science and 605 Technology, 9, 24.1-24.37.

606 Bligh, E. G., \& Dyer, W. J. (1959). A rapid method of total lipid extraction and purification. 607 Canadian Journal of Biochemistry Physiol., 37, 911-917.

608 Calder, P.C. \& Yaqoob, P. (2012). Marine omega-3 fatty acids and coronary heart disease. 609 Curr. Opin.Cardiol., 27, 412-419. 
610 Casado, V., Martin, D., Torres, C., \& Reglero, G. (2012). Phospholipases in food industry: a 611 review. Lipases Phospholipases Methods Protoc, 861, 495-523.

612 Cheatham, C. L., Colombo, J., \& Carlson, S. E. (2006). n-3 Fatty acids and cognitive and 613 visual acuity development: methodologic and conceptual considerations. Am. J. Clin. Nutr., $61483,1458 S-1466 S$.

615 Choi, S. J., Decker, E. A., Henson, L., Popplewell, L. M., Xiao, H., \& McClements, D. J. 616 (2011). Formulation and properties of model beverage emulsions stabilized by sucrose 617 monopalmitate: influence of $\mathrm{pH}$ and lyso-lecithin addition. Food Res. Int., 44, 3006-12.

618 Costa, M., Losada-Barreiro, S., Paiva-Martinsa, F., \& Bravo-Diaz, C. (2017). Physical 619 evidence that the variations in the efficiency of homologous series of antioxidants in 620 emulsions are a result if differences in their distribution. J Sci Food Agric, 97, 564-571.

621 EFSA Panel on Dietetic Products, Nutrition and Allergies (NDA) (2010). Scientific opinion on 622 dietary reference values for fats, including saturated fatty acids, polyunsaturated fatty acids, 623 monounsaturated fatty acids, trans fatty acids, and cholesterol. EFSA Journal, 8, 1461-1568.

624 Fang, Y., \& Dalgleish, D. G. (1996). Comparison of the effects of three different 625 phosphatidylcholines on casein-stabilized oil-in-water emulsions. Journal of the American Oil 626 Chemists'Society, 73(4), 437-442.

627 Faraji, H., McClements, D. J., \& Decker, E. A. (2004). Role of continuous phase protein on 628 the oxidative stability of fish oil-in-water emulsions. Journal of Agricultural and Food 629 Chemistry, 52, 4558-4564.

630 Frankel, E. N. (2012a). Chapter 1: Free radical oxidation. Lipid Oxidation (pp 22-23). (2nd 631 ed.). Philadelphia, USA: Woodhead Publishing. 
632 Frankel, E. N. (2012b). Chapter 2: Hydroperoxide formation. Lipid Oxidation (pp 43). (2nd 633 ed.). Philadelphia, USA: Woodhead Publishing.

634 García-Moreno, P. J., Horn, A. F., \& Jacobsen, C. (2014). Influence of casein-phospholipid 635 combinations as emulsifier on the physical and oxidative stability of fish oil-in-water 636 emulsions. Journal of Agricultural and Food Chemistry, 62(5), 1142-1152.

637 Gülcin, I. (2006). Antioxidant activity of caffeic acid (3,4-dihydroxycinnamic acid). Toxicology, $638 \quad 217,213-220$.

639 Horn, A. F., Nielsen, N. S., Andersen, U., Sogaard, L. H., Horsewell, A., \& Jacobsen, C. 640 (2011). Oxidative stability of $70 \%$ fish oil-in-water emulsions: Impact of emulsifiers and $\mathrm{pH}$. 641 European Journal of Lipid Science and Technology, 113, 1243-1257.

642 Jacobsen, C., Meyer, A. S., \& Adler-Nissen, J. (1998). Oxidation mechanisms in real food 643 emulsions: Method for separation of mayonnaise by ultracentrifugation. Journal of Food 644 Lipids, 5, 87-101.

645 Laguerre, M., Lopez Giraldo, L. J., Lecomte, J., Figueroa-Espinoza, M. C., Barea, B., Weiss, 646 J., Decker, E. A., \& Villeneuve, P. (2009). Chain length affects antioxidant properties of 647 chlorogenate esters in emulsion: The cutoff theory behind the polar paradox. J. Agric. Food 648 Chem., 57, 11335-11342.

649 Laguerre, M., Bayrasy, C., Lecomte, J., Chabi, B., Decker, E. A., Wrutniak-Cabello, C., 650 Cabello, G., \& Villeneuve, P. (2013). How to boost antioxidants by lipophilization? Biochimie, $65195,20-26$.

652 Liang, Y., Gillies, G., Patel, H., Matia-Merino, L., Ye, A., \& Golding, M. (2014). Physical 653 stability, microstructure and rheology of sodium-caseinatestabilized emulsions as influenced 
654 by protein concentration and nonadsorbing polysaccharides. Food Hydrocolloids, 36, 245655255.

656 McClements, J. D. (1999). Chapter 7: Emulsion stability. Food emulsions: Principles, practice 657 and techniques (pp. 196). (1st ed.). Boca Raton, Florida: CRC Press LCC.

658 McClements, D. J., Bai, L., \& Chung, C. (2017). Recent Advances in the Utilization of Natural 659 Emulsifiers to Form and Stabilize Emulsions. Annu. Rev. Food Sci. Technol., 8, 205-236.

660 McClements, D. J. \& Decker, E. (2018). Interfacial Antioxidants: A Review of Natural and 661 Synthetic Emulsifiers and Coemulsifiers That Can Inhibit Lipid Oxidation. J. Agric. Food 662 Chem., 66, 20-35.

663 O’Kennedy, B.T. (2011). Chapter 2: Caseins. In G. O. Phillips \& P. A. Williams (Eds.), 664 Handbook of Food Proteins (pp. 13-29). Cambridge, UK: Woodhead Publishing.

665 Samdani, G. K., McClements, D. J., \& Decker, E. A. (2018). Impact of Phospholipids and 666 Tocopherols on the Oxidative Stability of Soybean Oil-in-Water Emulsions. Journal of 667 Agricultural and Food Chemistry, DOI: 10.1021/acs.jafc.8b00677

668 Shadidi, F. \& Zhong, Y. (2011). Revisiting the Polar Paradox Theory: A Critical Overview. J. 669 Agric. Food Chem., 59, 3499-3504.

670 Shantha, N. C., \& Decker, E. A. (1994). Rapid, sensitive, iron based spectrophotometric 671 methods for determination of peroxide values of food lipids. Journal of AOAC International, $67277,421-424$.

673 Song, C., Shieh, C., Wu, Y., Kalueff, A., Gaikwad, S., \& Su, K. (2016). The role of omega-3 674 polyunsaturated fatty acids eicosapentaenoic and docosahexaenoic acids in the treatment of 
675 major depression and Alzheimer's disease: Acting separately or synergistically? Progress in 676 Lipid Research, 62, 41-54.

677 Sørensen, A.-D. M., Haahr, A.-M., Becker, E. M., Skibsted, L. H., Bergenståhl, B., Nilsson, L., 678 \& Jacobsen, C. (2008). Interactions between Iron, Phenolic Compounds, Emulsifiers, and pH 679 in Omega-3-Enriched Oil-in-Water Emulsions. J. Agric. Food Chem., 56, 1740-1750.

680 Sørensen, A.-D. M., Durand, E., Laguerre, M., Bayrasy, C., Lecomte, J., Villeneuve, P., \& 681 Jacobsen, C. (2014). Antioxidant properties and efficacies of synthesized alkyl caffeates, 682 ferulates and coumarates. Journal of Agricultural and Food Chemistry, 62, 12553-12562.

683 Sørensen, A.-D. M., Villeneuve, P., \& Jacobsen, C. (2017). Alkyl caffeates as antioxidants in 684 O/W emulsions: Impact of emulsifier type and endogenous tocopherols. Eur. J. Lipid Sci. 685 Technol., 119, 1600276.

686 Tesch, S. \& Schubert, H. (2002). Influence of increasing viscosity of the aqueous phase on 687 the short-term stability of protein stabilized emulsions. Journal of Food Engineering, 52, 305688312.

689 Yesiltas, B., Sørensen, A.-D. M., García-Moreno, P. J., Anankanbil, S., Guo, Z., \& Jacobsen, 690 C. (2018a). Combination of sodium caseinate and succinylated alginate improved stability of 691 high fat fish oil-in-water emulsions. Food Chemistry, 255, 290-299.

692 Yesiltas, B., García-Moreno, P. J., Sørensen, A.-D. M., Anankanbil, S., Guo, Z., Jacobsen, C. 693 (2018b). Effects of modified DATEMs with different alkyl chain lengths on improving oxidative 694 and physical stability of $70 \%$ fish oil-in-water emulsions. J. Agric. Food Chem., 66, $695 \quad 12512-12520$. 
696 Yesiltas, B., García-Moreno, P. J., Sørensen, A.-D. M., Akoh, C. C., \& Jacobsen, C. (2019).

697 Physical and oxidative stability of high fat fish oil-in-water emulsions stabilized with sodium 698 caseinate and phosphatidylcholine as emulsifiers. Food Chemistry, 276, 110-118.

699 Zhu, Z., Zhao, C., Yi, J., Liu, N., Cao, Y., Decker, E. A., \& McClements, D. C. (2018). Impact

700 of Interfacial Composition on Lipid and Protein Co-Oxidation in Oil-in-Water Emulsions

701 Containing Mixed Emulisifers. J. Agric. Food Chem., 66, 4458-4468 
Table 1. Emulsion codes, descriptions and experimental design with the content of emulsions

\begin{tabular}{llccc}
\hline Emulsion code & Description & $\begin{array}{c}\text { Soy PC } \\
(\%, \mathrm{w} / \mathrm{w})\end{array}$ & $\begin{array}{c}\text { Modified PC } \\
(\%, \mathrm{w} / \mathrm{w})\end{array}$ & $\begin{array}{c}\text { caffeic acid } \\
(\mathrm{ppm})\end{array}$ \\
\hline 1 CAS & CAS only & - & - & - \\
2 PC_com & CAS + com PC & 1.27 & - & - \\
3 PC_C14_360 & CAS + com PC + mod PC C14 & 1.15 & 0.12 & $360^{*}$ \\
4 PC_C14_1080 & CAS + com PC + mod PC C14 & 0.90 & 0.37 & $1080^{*}$ \\
5 PC_C14_2160 & CAS + com PC + mod PC C14 & 0.52 & 0.75 & $2160^{*}$ \\
6 PC_C16_360 & CAS + com PC + mod PC C16 & 1.14 & 0.13 & $360^{*}$ \\
7 PC_C16_1080 & CAS + com PC + mod PC C16 & 0.88 & 0.39 & $1080^{*}$ \\
8 PC_C16_2160 & CAS + com PC + mod PC C16 & 0.48 & 0.79 & $2160^{*}$ \\
9 PC_com_caf_360 & CAS + com PC + caffeic acid & 1.27 & - & 360 \\
10 PC_com_caf_2160 & CAS + com PC + caffeic acid & 1.27 & - & 2160 \\
\hline All
\end{tabular}

All the emulsions have $70 \%(\mathrm{w} / \mathrm{w})$ fish oil, $2.8 \%(\mathrm{w} / \mathrm{w})$ total emulsifier content and the ratio

between CAS to PC is 1.2, which results in $1.53 \%(\mathrm{w} / \mathrm{w})$ CAS, except for 1CAS as it includes only CAS $(2.8 \%, w / w)$. Soy PC was substituted with modified PCs in different ratios in order to obtain different concentrations of caffeic acid in the final emulsion (caffeic acid (ppm)).

${ }^{*}$ Free caffeic acid was not added in emulsion 3 to 8 . Concentration was calculated according to the added modified PC, which had caffeic acid attached to the compound itself. 
Table 2. Droplet size, apparent viscosity, zeta potential, protein in the aqueous phase, and protein surface load results of emulsions

\begin{tabular}{|c|c|c|c|c|c|c|}
\hline Emulsion code & $\begin{array}{c}\mathrm{D}[3,2] \\
(\mu \mathrm{m}) \\
(\text { Day } 1) \\
\end{array}$ & $\begin{array}{c}\mathrm{D}[4,3] \\
(\mu \mathrm{m}) \\
(\text { Day } 1) \\
\end{array}$ & $\begin{array}{c}\text { Apparent viscosity } \\
\text { (mPa.s) at } 20 \mathrm{~s}^{-1} \\
\text { (Day 1) } \\
\end{array}$ & $\begin{array}{c}\text { Zeta potential } \\
\text { (mV) } \\
\text { (Day 2) }\end{array}$ & $\begin{array}{c}\text { Protein in the } \\
\text { aqueous phase (g) } \\
\text { (Day 4) }\end{array}$ & $\begin{array}{c}\text { Protein surface } \\
\text { load }\left(\mathrm{mg} / \mathrm{m}^{2}\right) \\
\text { (Day 4) }\end{array}$ \\
\hline $1 \mathrm{CAS}$ & $1.5 \pm 0.7^{b}$ & $8.8 \pm 0.3^{\mathrm{d}}$ & $2457 \pm 11^{d}$ & (-) $61.9 \pm 1.4^{\mathrm{a}}$ & $1.70 \pm 0.01^{\mathrm{c}}$ & $4.35 \pm 0.05^{\mathrm{a}}$ \\
\hline 2 PC_com & $10.8 \pm 0.2^{d}$ & $17.0 \pm 0.2^{9}$ & $923 \pm 14^{\mathrm{c} *}$ & (-) $52.8 \pm 4.4^{\text {cd }}$ & $0.95 \pm 0.34^{b}$ & $16.47 \pm 9.67^{b}$ \\
\hline 3 PC_C14_360 & $8.3 \pm 0.1^{c}$ & $11.7 \pm 0.0^{\dagger}$ & $939 \pm 7^{c *}$ & (-) $59.3 \pm 5.2^{\mathrm{ab}}$ & $0.94 \pm 0.05^{b}$ & $12.81 \pm 1.13^{b}$ \\
\hline 4 PC_C14_1080 & $1.0 \pm 0.0^{\mathrm{ab}}$ & $8.0 \pm 0.1^{c}$ & $841 \pm 9^{b *}$ & (-) $56.3 \pm 1.4^{\mathrm{bc}}$ & $0.91 \pm 0.01^{b}$ & $1.63 \pm 0.01^{\mathrm{a}}$ \\
\hline 5 PC_C14_2160 & $0.7 \pm 0.1^{a *}$ & $5.0 \pm 0.1^{a *}$ & $971 \pm 3^{c_{*}}$ & (-) $52.2 \pm 1.1^{\mathrm{cd}}$ & $0.91 \pm 0.01^{b}$ & $1.13 \pm 0.02^{\mathrm{a}}$ \\
\hline 6 PC_C16_360 & $8.0 \pm 0.1^{\mathrm{c*}}$ & $11.9 \pm 0.0^{\dagger}$ & $943 \pm 36^{\mathrm{c} *}$ & (-) $52.1 \pm 1.2^{\text {cd }}$ & $0.82 \pm 0.10^{\mathrm{ab}}$ & $14.80 \pm 2.05^{b}$ \\
\hline 7 PC_C16_1080 & $1.8 \pm 0.3^{\S}$ & $9.5 \pm 0.2^{e *}$ & $740 \pm 32^{a *}$ & (-) $47.0 \pm 3.9^{e}$ & $0.81 \pm 0.06^{\mathrm{ab}}$ & $3.40 \pm 0.30^{\mathrm{a}}$ \\
\hline 8 PC_C16_2160 & $1.1 \pm 0.3^{\S}$ & $6.7 \pm 0.3^{b}$ & $777 \pm 83^{\mathrm{ab} *}$ & (-) $48.8 \pm 1.3^{\mathrm{de}}$ & $0.61 \pm 0.19^{\mathrm{a}}$ & $2.64 \pm 0.54^{\mathrm{a}}$ \\
\hline 9 PC_com_caf_360 & $11.1 \pm 0.2^{d}$ & $17.8 \pm 0.1^{n}$ & $844 \pm 44^{b_{*}}$ & (-) $48.8 \pm 1.9^{\mathrm{de}}$ & $0.96 \pm 0.01^{b}$ & $16.59 \pm 0.17^{b}$ \\
\hline 10 PC_com_caf_2160 & $10.9 \pm 0.6^{d}$ & $18.4 \pm 0.0^{\prime}$ & $831 \pm 93^{b *}$ & (-) $49.4 \pm 3.0^{\mathrm{de}}$ & $1.00 \pm 0.08^{b}$ & $15.00 \pm 2.29^{b}$ \\
\hline
\end{tabular}

*Significant changes happened in droplet size and viscosity during 12 days of storage at $p<0.05$.

a-f Letters indicate the significant differences between samples for the same physical parameter.

§There was only one replicate for these 2 samples. 

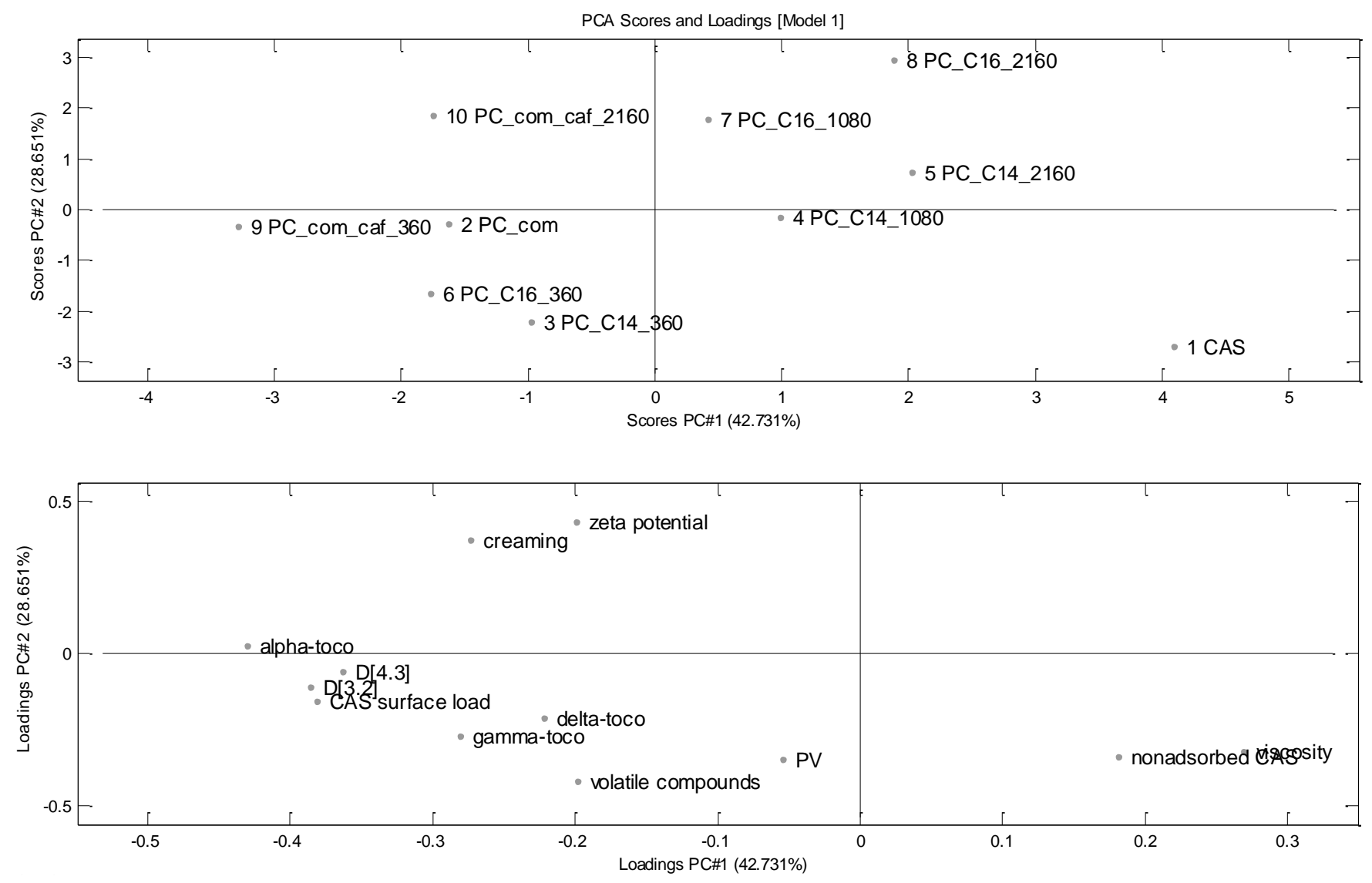

Figure 1. PCA scores and loading were plotted using the results of oxidation parameters (PV, tocopherols, volatiles) and physical parameters ( $[3,2], D[4,3]$, viscosity, zeta potential, creaming, non-adsorbed CAS and CAS surface load). 


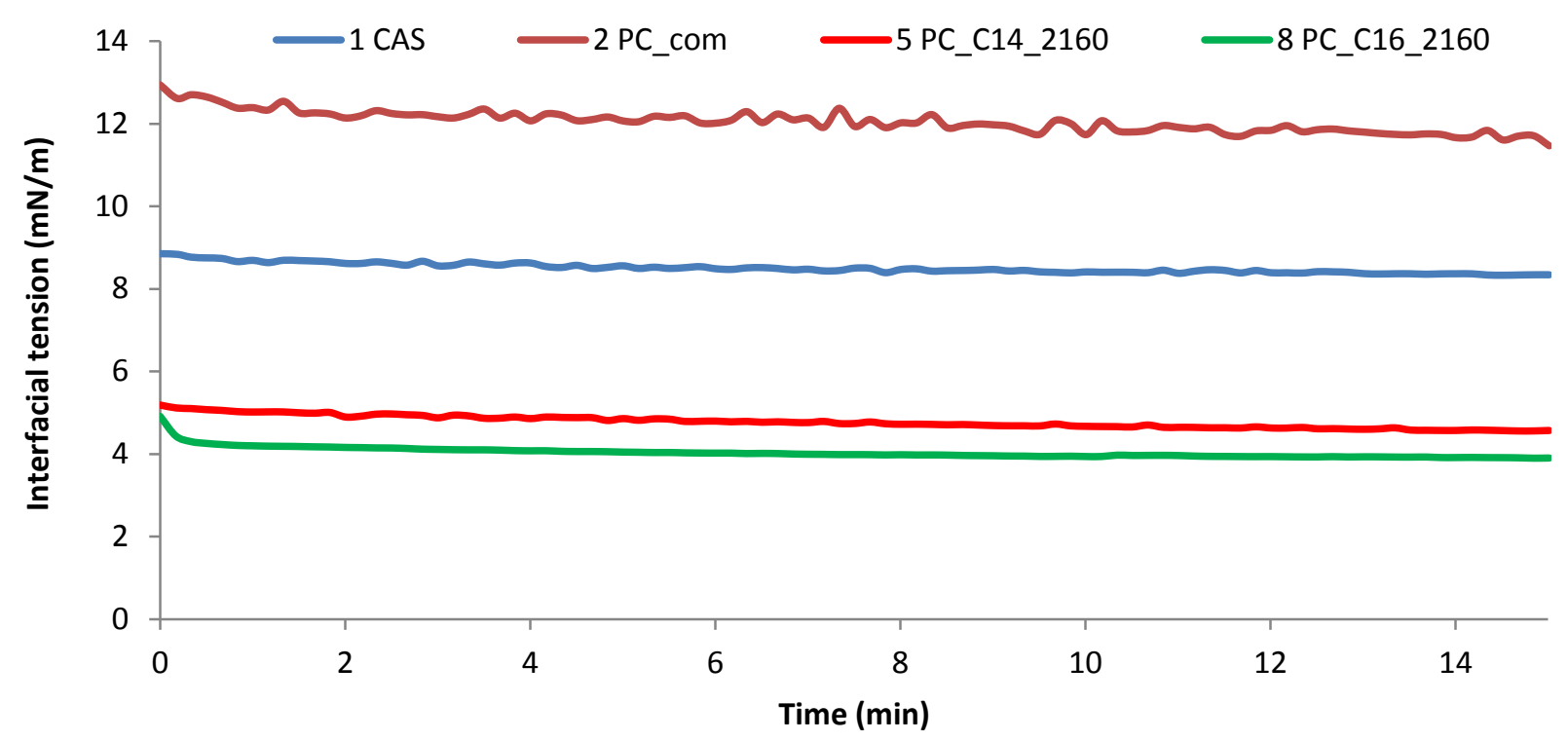

The oil-water interfacial tension without emulsifiers was $26 \mathrm{mN} / \mathrm{m}$ during 15 min for MCT oil/water. Relative standard deviation was lower than $6 \%$ in all samples.

Figure 2. Interfacial tension of emulsifier combinations 


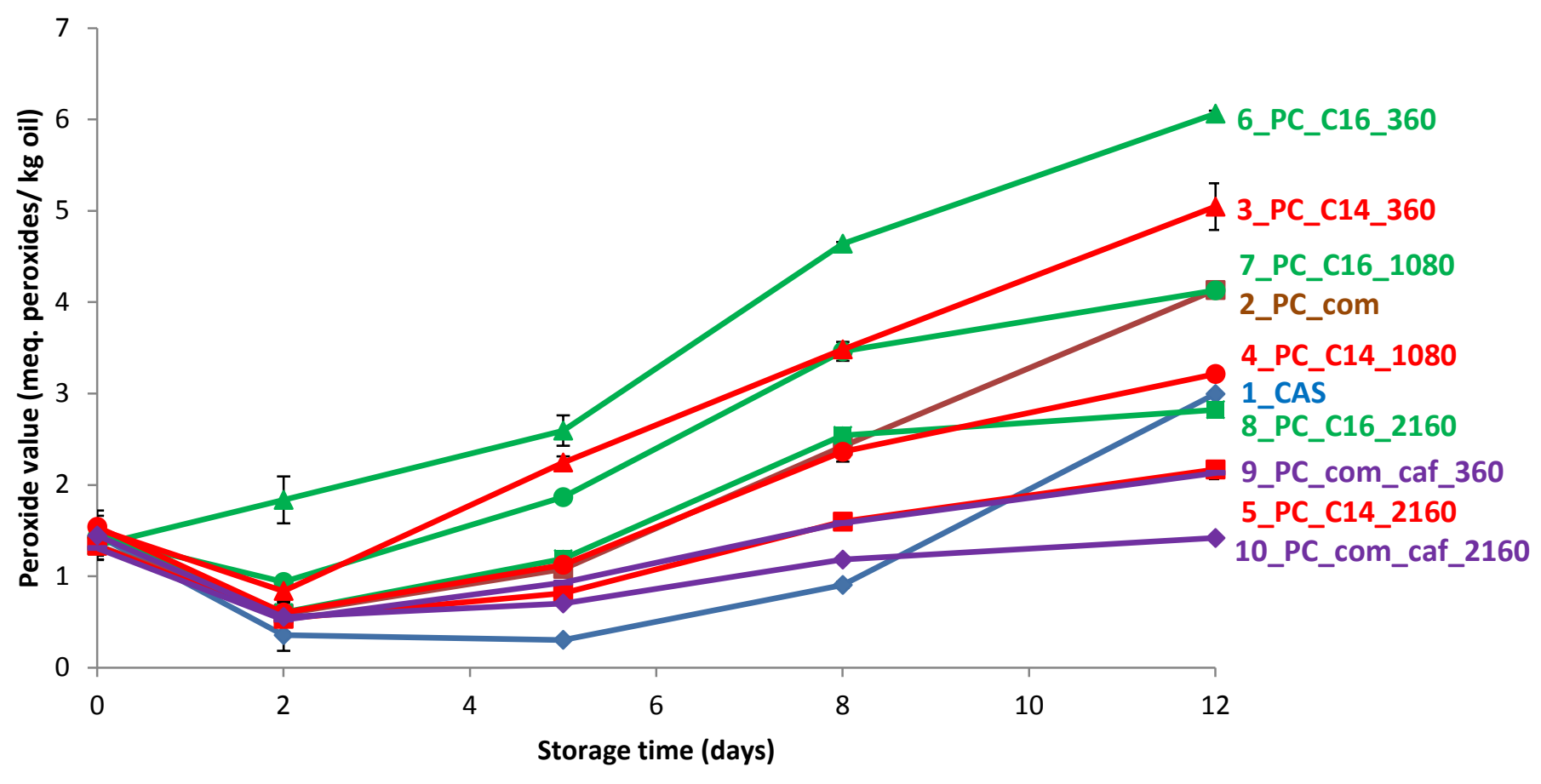

Figure 3. Formation of primary oxidation product in the emulsions during 12 days of storage. 


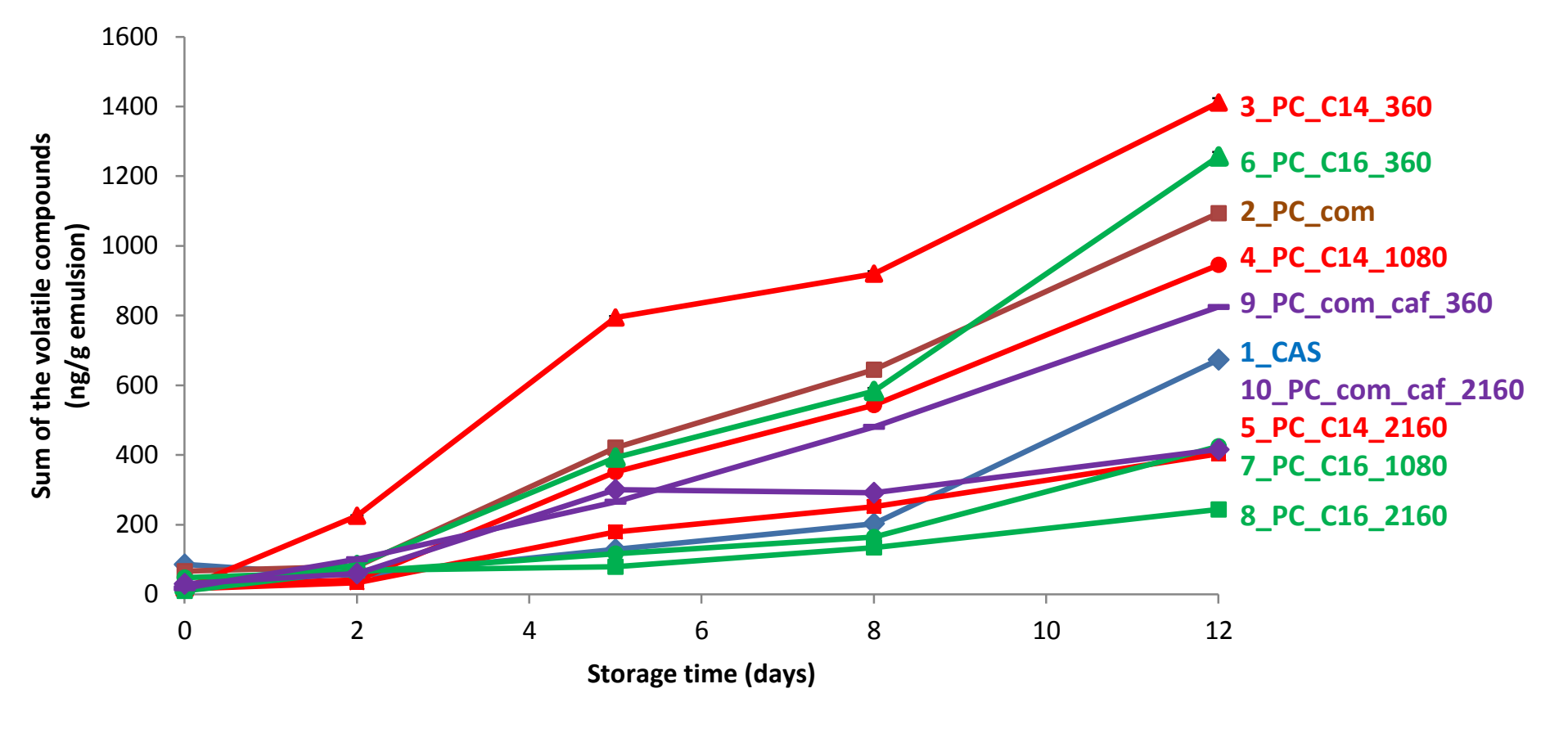

Figure 4 . Sum of the volatile secondary oxidation products formed in emulsion samples during
12 days of storage

Figure 4 . Sum of the volatile secondary oxidation products formed in emulsion samples during
12 days of storage

Storage time (days)

Figure 4. Sum of the volatile secondary oxidation products formed in emulsion samples during
12 days of storage

\author{
12 days of storage
}

Figure 4 . Sum of the volatile secondary oxidation products formed in emulsion samples during
12 days of storage

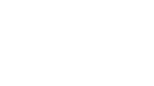


Supplementary Material
Click here to download Supplementary Material: Supplementary material.pdf

Supplementary Material
Click here to download Supplementary Material: Supplementary material.pdf

\author{
Click here to download Supplementary Material: Supplementary material.pdf
}

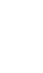

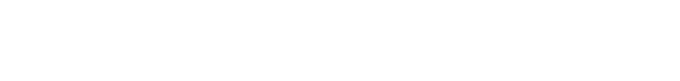

$\sqrt{2}$

.

(1)

(1)

(1)

(1)

(1)

(1)

(1)

(1)

(1)

(1)

(1)

.

.

.

.

.

.

.

.

.

.

.

.

.

.

.

.

.

.

.

.

.

. 